\title{
PRIMARY HEADACHES IN OBESE PATIENTS
}

\author{
Mario Fernando Prieto Peres', Daniel Diniz Gonçalves Lerário', \\ Arthur Belarmino Garrido ${ }^{1,2}$, Eliova Zukerman ${ }^{1}$
}

\begin{abstract}
Background and Objective: Obesity is a major public health problem worldwide. Little is known about the prevalence and impact of headache disorders in obese patients. The objective of this study was to assess the prevalence of primary headaches in obese patients and controls. Method: Seventy-four consecutive obese patients from the obesity surg eryservice were studied, and compared to controls with body mass index less than 25 . Results: Fifty-six patients $(75 \%)$ had a headache diagnosis, 49 migraine $(66 \%)$, 7 tension-type headache (9\%), 36 (48\%) had incapacitating headaches. Conclusion: Primaryheadaches are more common and incapacitating in obese patients than controls, migraine is the most important diagnosis in this population. Headaches should be properly diagnosed and treated in obese patients.
\end{abstract}

KEY WORDS: headache, obesity, migraine.

\section{Cefaléias primárias em pacientes obesos}

RESUMO - Introdução: Obesidade é um problema de saúde publica relevante em todo o mundo. Pouco se sabe sobre a prevalencia e impacto das cefaléias em pacientes obesos. Objetivo: Avaliar a prevalência de cefaléias primárias em pacientes obesos. Método: Setenta e quatro pacientes consecutivos originários de um centro de tratamento de obesidade foram estudados e comparados com controles com índices de massa corporal menores que 25. Resultados: Cinquenta e cinco pacientes (75\%) apresentaram algum diagnóstico de cefaléia primária, 49 enxaqueca (66\%), 7 cefaléia do tipo tensional $(9 \%), 36(48 \%)$ tiveram cefaléias incapacitantes. Conclusão: Cefaléias primárias são mais comuns e incapacitantes em pacientes obesos que controles, a enxaqueca é o diagnóstico mais freqüente nesta população. Cefaléias devem ser adequadamente diagnosticadas e tratadas em pacientes obesos.

PALAVRAS-CHAVE: cefaléia, obesidade, enxaqueca.

Obesity is defined by a body-mass index (weight divided by square of the height) of $30 \mathrm{~kg} \mathrm{~m}^{-2}$ or greater. In the past decades, worldwide prevalence rates of obesity and overweight have risen to epidemic proportions, ranging from $7 \%$ in France to $32.8 \%$ in Brazil 1 . It has now reached $31 \%$ in the United States (US) and over $25 \%$ in many other industrialized nations ${ }^{2}$. A total of $65 \%$ of adults and $16 \%$ of adolescents in the US are now overweight ${ }^{3}$. Obesity is a major public health problem worldwide contributing to increased morbidity and mortality. Obesity is now so common within the world's population that it is beginning to replace undern u trition and infectious diseases as the most significant contributor to ill health. The economic burden of obesity-related illness in many countries is substantial, with estimates ranging from 2 to $7 \%$ of total health-care expenditures and billions of dollars in direct and indirect costs to society 4 .

Obesity and overweight are associated with inc reases in overall mortality as well as a number of ch ronic conditions, including diabetes mellitus, cardiovascular disease, cancer, osteoarthritis, gastro esophageal reflux disease, low back pain and sleepbreathing disorders 5 .

The global epidemic of obesity results from a combination of genetic susceptibility, increased availability of high-energy foods and decreased requirement for physical activity in modern society. Obesity should no longer be re $\mathrm{g}$ a rded simply as a cosmetic problem affecting certain individuals, but an epidemic that threatens global well being.

Headache and obesity are linked in several ways. Headache conditions such as idiopathic intracranial hypertension ${ }^{6}$ and headache secondary to sleep apnea syndro $\mathrm{m} \mathrm{e}^{7}$ a re highly related to obesity, in addition, it is a risk factor for sexual headaches ${ }^{8}$. Medications for obesity treatment (sibutramine) are known to cause headaches, on the other hand, migraine preventives may cause weight gain or loss ${ }^{9}$. Little is known about the prevalence and impact of headache disorders in obese patients.

'Instituto Israelita de Ensino e Pesquisa Albert Einstein, São Paulo SP, Brazil, ${ }^{2}$ Hospital Beneficência Portugesa, São Paulo SP, Brazil Received 20 April 2005, received in final form 24 June 2005. Accepted 15 August 2005.

Dr. Mario Fernando Prieto Peres - Instituto Israelita de Ensino e Pesquisa Albert Einstein - Avenida Albert Einstein, $627 / 701$ 05651-901 São Paulo SP - Brasil. E-mail: marioperes@yahoo.com 


\section{METHOD}

We studied 74 consecutive obese patients from the obesity surgery service at the Hospital Beneficência Portuguesa, São Paulo. Gender, age, race, body mass index (BMI) were ascertained. The Epworth Sleepiness Scale (ESS) was applied to all patients. Headache features, frequency, intensity, and attack duration, as other variables needed for a primary headache diagnosis based on the IHS diagnostic criteria ${ }^{10}$ were obtained. Clinical and ne urological examination as well as clinical history were obtained by a headache specialist.

Patients BMI were divided into 5 categories: 1) normal, BMI from 19 to 25,2) overweight, 26 to 30, 3) obesity grade I, 31 to 35,4$)$ obesity grade II, 36 to 40,5 ) obesity grade III, $\geq 41$ (Table 1). Age and gender matched controls from the general population with normal BMls were enrolled.

$\mathrm{F}$ i b romyalgia was diagnosed according to the American College of Rheumatology diagnostic criteria ${ }^{11}$. All patients and controls signed a written informed consent, the study was approved by the local ethics committee. The Chi-square test, one-way ANOVA, Pearson correlation test, and Mann Whitney Rank Sum test were used for the statistical analysis. Results were considered significant at a $\mathrm{p}$ level $<0.05$.

\section{RESULTS}

Age ranged from 14 to 69 , mean age 38.4 (61 women, 13 men), mean body mass index was 43 . Age-matched control patients had a mean age of 39.2 (18 to 65), 60 women, 10 men, mean BMI 22, range 19 to 24 . Five patients were overweight, 12 patients had obesity I, 10 obesity II, and 47 obesity III (Table 1). Thirty-six patients (48\%) had incapacitating headaches defined when patients re $p$ o rted a significant disability attributed by their headaches.

Only 10 patients had morning headaches. The mean Epworth Sleepiness Scale was 7.4 in patients and 3.5 in controls, 26 patients (35\%) and 10 controls $(14 \%)$ had the score higher than 10 , indicating excessive daytime sleepiness $(p<0.005)$. Fifty-
Table 1. Patients distribution according to $B M I$, and obesity cat egories (normal, overweight, obesity grades I, II, and III).

\begin{tabular}{lccc}
\hline Obesity & BMI & $\mathrm{N}$ & $\%$ \\
\hline normal & $19-25$ & - & - \\
Overweight & $26-30$ & 5 & 6.8 \\
Obesity I & $31-35$ & 12 & 16.2 \\
Obesity II & $36-40$ & 10 & 13.5 \\
Obesity III & $>41$ & 47 & 63.5 \\
\hline
\end{tabular}

six patients $(75 \%)$ had a lifetime primary headache diagnosis, compared to 30 controls $(42 \%) p<0.001$. Forty-nine patients were diagnosed with migraine (66\%), 7 tension-type headache (9\%). Thirty-five patients had migraine without aura (47\%) patients, 5 migraine with aura, 7 chronic migraine, 1 menstrual migraine, 1 migrainous disorder, 2 chronic and 5 episodic tension-type headache (Table 2). Five patients were diagnosed with fibromyalgia, all with chronic migraine. Nine (12.2\%) chronic daily headache patients (chronic migraine and chro nic tension-type headache) were identified. Three patients were overusing acute medications.

BMI significantly correlate with age $(p<0.04, r=$ 0.239 ), but did not correlate with headache frequency, intensity, and ESS scores. The ESS scores did not correlate with headache frequency and intensity. Primary headache diagnosis were as prevalent in obesity grade III as in overweight and obesity grades I and II. No significant diffe rences in headache diagnosis were found when patients with excessive daytime sleepiness were compared with those without it. Obese women had significantly more pri$m$ a ry headache diagnosis than men $(p<0.01)$. Patients with incapacitating headaches did not differ regarding BMI and ESS when compared to those with less disabling pain.

\section{DISCUSSION}

Primary headache disorders are very common and incapacitating in obese patients. To our knowl-

Table 2. Primary headache diagnosis among obese patients and controls.

\begin{tabular}{|c|c|c|c|c|c|c|c|c|}
\hline \multirow[b]{2}{*}{ Diagnosis } & \multicolumn{4}{|c|}{ Obesity } & \multicolumn{4}{|c|}{ Controls } \\
\hline & & $\mathrm{N}$ & & $\%$ & & $\mathrm{~N}$ & & $\%$ \\
\hline none & 18 & & 24.3 & 24.3 & 40 & & 57.2 & 57.2 \\
\hline migraine & 49 & & 66.2 & & 13 & & 18.5 & \\
\hline migraine without aura & & 35 & & 47.3 & & 5 & & 7.1 \\
\hline chronic migraine & & 7 & & 9.5 & & 1 & & 1.4 \\
\hline migraine with aura & & 5 & & 6.7 & & 2 & & 2.9 \\
\hline mentrual migraine & & 1 & & 1.3 & & 1 & & 1.4 \\
\hline migrainous disorder & & 1 & & 1.3 & & 4 & & 5.7 \\
\hline Tension-type headache & 7 & & 9.5 & & 17 & & 24.3 & \\
\hline chronic & & 2 & & 2.7 & & 1 & & 1.4 \\
\hline episodic & & 5 & & 6.7 & & 16 & & 22.9 \\
\hline Total & 74 & 74 & 100 & 100 & 70 & 70 & 100 & 100 \\
\hline
\end{tabular}


edge, this is the first study assessing primary headache diagnosis in obese patients. Migraine is the most common diagnosis, chronic daily headache (chronic migraine and chronic tension-type headache) was present in $12.2 \%$ of obese patients. Comparing to populational studies the prevalence rates of daily headaches would be not higher than $6 \%{ }^{12}$. The previously unrecognized high prevalence of headache disorders in obese patients implies important changes in the management of obesity. The quality of life in obese patients with incapacitating primary headache disorders may be substantially affected, there fo reheadaches must be p roperly diagnosed and treated. Diagnosis of headache disorders in this study was based on clinical examination and medical history, however we cannot exclude cases of idiopathic intracranial hypertension without papilledema.

Sleep breathing disorder has been long recognized as a cause of headache ${ }^{13}$. In our study we failed to demonstrate a correlation between excessive daytime sleepiness, the hallmark of the sleep apnea syndrome (SAS), and headache diagnosis, intensity and frequency. Morning headaches, the most important feature of headache attribute to SAS rarely occuned in our population. It is not likely that sleep breathing disorders may play a pivotal role in headaches of obese patients. Other factors including psychiatric comorbid disorders (anxiety and mood disorders) could also play a role in headache occurrence in this population. Associated conditions such as hypertension, diabetes, and dyslipidemia can theoretically be involved. Further studies are needed to clarify those issues.

Peres et al. ${ }^{14}$ postulated a hypothalamic involvement in chronic migraine patients. The hypothalamus is clearly important in feeding behavior regulation, and in obesity pathophysiology, so it may be a probable site related to the mechanisms of headache in obesity. The study of recently reported neuropeptides involved in the development of obesity in animal models and neural pathways concerned in the regulation of obesity may help clarify headache pathophysiology ${ }^{15}$. Nevertheless, environmental factors should not be forgotten - the epidemic of obesity witnessed during the past 20 years has emerged from a relatively constant genetic pool. The identification of mechanisms involved in the etiology and pathogenesis of obesity and headache disorders remains critically important for the immediate future of both disorders.

The headache management in obesity may be difficult, treatment limitations occur, but therapeutic windows of opportunity arise. Medications such as sibutramine should be avoided. Other agents commonly used for the treatment of associated disorders in obesity, such as statins in dyslipidemia, nitrates in coronary artery disease, may also cause headaches. Migraine treatments possibly causing weight gain, such as tryciclics, flunarizine, divalproex, and corticostercids may be used with caution. Topiramate is a potential preventive treatment to be used in obese patients with headache disorders.

It is unknown whether higher doses of migraine medications should be recommended in obese patients, but clinicians should keep this possibility in mind.

Nonpharmacological approaches such as successfully encouraging increased physical activity remain paramount for the prevention of obesity and its associated diseases, it may also help headache contrd. In conclusion, primary headaches are common and incapacitating in obese patients. Migraine is the most common primary headache in obese patients. The hypothalamus may be the primary site linking the pathophysiology of headache in obesity. Headaches disorders should be properly diagnosed and treated in obese patients.

\section{REFERENCES}

1. Filozof C, Gonzalez C, Sereday M, et al. Obesity prevalence and trends in Latin-American countries. Obes Rev 2001;2:99-106.

2. Flegal KM, Carroll MD, Ogden CL, et al. Prevalence and trends in obesity among US adults, 1999-2000. JAMA 2002;288:1723-1727.

3. Ogden CL, Flegal KM, Carroll MD, et al. Prevalence and trends in overweight among US children and adolescents, 1999-2000. JAMA 2002;288: 1728-1732.

4. Birmingham CL, Muller JL, Palepu A, et al. The cost of obesity in Canada. CMAJ, 1999;160:483-488.

5. Kopelman PG. Obesity as a medical problem. Nature 2000;404:635-643.

6. Wang SJ, Silberstein SD, Patterson S, et al. Idiopathic intracranial hypertension without papilledema: a case-control study in a headache center. Neurology 1998;51:245-249.

7. Dodick DW, Eross EJ, Parish JM. Clinical, anatomical, and physiologic relationship between sleep and headache. Headache 2003;43:282-292.

8. Akpunonu BE, Ahrens J. Sexual headaches: case report, review, and treatment with calcium blocker. Headache 1991;31:141-145.

9. Loewinger LE, Young WB. Headache preventives: effect on weight. Neurology 2002;58[7 Suppl 3];A286.

10. Headache Classification Committee of the International Headache Society. Classification and diagnostic criteria for headache disorders, cranial neuralgias, and facial pain, Second edition. Cephalalgia. 2004(Suppl 1):1-160.

11. Wolfe F, Smythe HA, Yunus MB, et al. The American College of Rheumatology 1990 criteria for the classification of fibromyalgia: report of the Multicenter Criteria Committee. Arthritis Rheum 1990;33:160-172.

12. Queiroz LP, Blank N, Barea, LM. A population-based study of chronic headache in Florianopolis, Brazil. Cephalalgia, 2003;23:598.

13. Sand T, Hagen K, Schrader H. Sleep apnoea and chronic headache. Cephalalgia 2003;23:90-95.

14. Peres MF, Sanchez dR, Seabra ML, et al. Hypothalamic involvement in chronic migraine. J Neurol Neurosurg Psychiatry. 2001;71:747-751.

15. Small CJ, Parkinson JR, Bloom SR. Novel therapeutic targets for appetite regulation. Curr Opin Investig Drugs 2005;6:369-372. 